\title{
Effects of High Temperature and Strong Light Combine Stress on Yield and Quality of Early Indica Rice with Different Amylose Content during Grout Filling
}

\author{
Xiaofeng Ai ${ }^{1}$, Ruoyu Xiong ${ }^{1}$, Xueming Tan ${ }^{1}$, Haixia Wang ${ }^{1}$, Jun Zhang ${ }^{2}$, Yongjun Zeng ${ }^{1}$, Xiaohua Pan ${ }^{1}$, \\ Qinghua Shi ${ }^{1}$, Taoju Liu ${ }^{1}$ and Yanhua Zeng ${ }^{1,}$
}

${ }^{1}$ Ministry of Education and Jiangxi Key Laboratory of Crop Physiology, Ecology and Genetic Breeding, Jiangxi Agricultural University, Nanchang, 330045, China

${ }^{2}$ Institute of Crop Sciences, Chinese Academy of Agricultural Sciences, Beijing, 100081, China

${ }^{*}$ Corresponding Author: Yanhua Zeng. Email: zyh74049501@163.com

Received: 16 July 2021 Accepted: 09 October 2021

\begin{abstract}
High temperature (HT) accompanied with strong light (SL) often occurs in early indica rice production during grout filling stage in Southern China, which accelerates grain ripening. Two indica rice cultivars with different amylose content (Zhongjiazao17, ZJZ17, high amylose content; Xiangzaoxian45, XZX45, low amylose content) were grown under control (CK), HT, and $\mathrm{HT}+\mathrm{SL}$ conditions during grout filling to determine the effects on grain yield and quality of rice. The results showed that compared with CK, HT and HT+SL significantly reduced the 1000-grain weight and filled grain rate whether in high or low amylose content early indica rice cultivars during grout filling, resulting in a significantly lower grain yield. Meanwhile, HT and HT+SL significantly decreased the milled rice rate, brown rice rate and head rice rate, whereas significantly increased chalky rate and chalky degree; and breakdown decreased and setback, pasting temperature increased in the cultivars, leading to the poor processing, appearance and cooking and eating quality of early indica rice cultivars. Compared with HT, the yield of ZJZ17 was significantly decreased under HT+SL, due to the lower 1000-grain weight. However, the effect of $\mathrm{HT}+\mathrm{SL}$ on rice quality varied in the cultivars. In general, the yield and rice quality of ZJZ17 were relatively poor under HT+SL. Our results suggested that HT and HT+SL during grout filling had significant damage to the yield and quality of early indica rice cultivars, especially HT+SL, while the high amylose cultivar ZJZ17 showed a higher negative effect under $\mathrm{HT}+\mathrm{SL}$.
\end{abstract}

\section{KEYWORDS}

High temperature-strong light double stress; yield; appearance quality; cooking and eating quality

\section{Highlights}

- HT and HT+SL during grout filling deteriorated yield and quality in the cultivars.

- High amylose cultivar ZJZ17 had relatively poor yield and quality of rice under HT+SL.

- SL can promote the synthesis of amylose in the cultivars under HT condition. 


\section{Introduction}

Rice (Oryza sativa L.) is one of the world's major food crops; the improvement of rice quality is increasingly closely related to people's life [1]. Previous studies have shown that the global warming caused by the greenhouse effect has threatened rice production in many countries and regions; In recent years, more and more attention has been paid to the stability of rice quality under extreme climate $[2,3]$. The grain quality of rice includes processing quality, appearance quality, cooking and eating quality (CEQ) and nutritional quality [4]. More and more consumers are interested in the CEQ with the improvement of people's living standard [5,6]. Because the content of amylose is closely related to the quality of CEQ, the change of amylose content caused by extreme climate has a great influence on the CEQ [4]. Therefore, it is very important that the production of high-quality rice in extreme weather conditions.

The grain quality of rice is mainly affected by environmental factors at the grout filling stage such as temperature and light [7-9]. A number of studies have shown that high-temperature treatment during grout filling period can accelerate grout filling rate, thus affecting grain development, leading to decreased yield and amylose content, and worse processing quality and appearance quality [10,11]. However, the temperature during grout filling also changed the contents of starch, storage protein, amino acids and fatty acids in rice caryopsis, which affected rice quality [12]. Rice protein is rich in essential amino acids and has a good balance among various amino acids. It is also an excellent dietary nutrient. Moreover, it is generally assumed that total protein will increase under high-temperature conditions [13]. Under the global warming trend, extreme high-temperature events are becoming more frequent, which affect rice yield and grain quality by altering the 1000-grain weight and filled grain rate, and head rice rate, amylose content, chalky degree and RVA viscosity characteristics of rice [14]. Our previous study also reported that experimental warming during the rice growing period in the field condition could change the yield and quality of rice in the double indica rice cropping system in Southern China [2].

Furthermore, light intensity is the second major environmental factor that determines the grain development characteristics of rice. Too low light will significantly lead to yield loss and poor grain quality, especially in the grout-filling stage [15]. Ren et al. [16] put forward that light intensity also determined the yield and quality of rice. Most past studies mainly focused on the effect of low light stress on rice quality, and the main result was that low light reduced the appearance and processing quality of rice during grout filling stage $[8,15]$. In addition, early indica rice in southern China often encountered meteorological disaster for high temperature and strong light combined stress during grout filling, affecting rice yield and the formation of grain quality [17]. However, this is very limited information on the response mechanism of early indica rice to grain yield and quality under high temperature and strong light combine stress.

Amylose affects the CEQ of rice mainly by changing the quality of rice starch, and is closely related to the external environment such as high temperature. Zhong et al. [6] put forward that high temperature decreased amylose content in low-amylose content cultivars. In addition, early indica rice cultivars in Southern China have been breeding for the trend on high grain quality with low amylose content in recent years. The objectives of this study are to determine the effect of high temperature and strong light on the grain yield and quality such as processing, appearance, cooking and eating quality and nutritional quality of rice cultivars with different amylose content at the grout filling stage, and to clarify the different responses of the rice cultivars to treatments. Therefore, we established HT+SL, HT and CK as the control in the climate chamber during grout filling of two early indica rice cultivars with high or low amylose content through the pot experiment. This study could provide a reference for improving the grain quality of early indica rice under high temperatures and strong light during grout filling. 


\section{Materials and Methods}

\subsection{Experimental Design and Crop Cultivation}

The pot experiment was carried out during the growth period from March to July in 2019 at Science and Technology Demonstration Park of Jiangxi Agricultural University (JXAU, Jiangxi Province, China). Two indica rice cultivars Xiangzaoxian 45 (XZX45, good grain quality with low amylose content) and Zhongjiazao 17 (ZJZ17, poor grain quality with high amylose content) were used for early rice cultivation materials. They are both inbred indica rice cultivars with good light reception ability for sensitivity to high temperature, and are provided by Jiangxi Modern Seed Industry Co., Ltd., China. Outdoor meteorological data during the rice growing period are shown in Fig. 1. The pot experiment adopted crack zone design with temperature and light treatment (CK, HT and HT+SL) was treated as the main plots with sixty pots for each treatment, and the cultivars were the subplots with ninety pots for each cultivar. Every 10 pots (three seedlings per hole, two holes per pot) of each cultivar were used as a sample, and the treatment was repeated three times. Three well-controlled walk-in climate chambers (each climate chamber has two floors of $24 \mathrm{~m}^{2}$ and each floor is $140 \mathrm{~cm}$ height) were set up during rice grout filling, which the temperature and lighting settings are as follows: Ambient conditions (CK): the average temperature is maintained at $24^{\circ} \mathrm{C}\left(28^{\circ} \mathrm{C} / 20^{\circ} \mathrm{C}\right.$, day/night temperature), and the normal light intensity was set at $1000 \mu \mathrm{mol} \cdot \mathrm{m}^{-2} \cdot \mathrm{s}^{-1}$. High temperature and normal light (HT): the average temperature is maintained at $32^{\circ} \mathrm{C}\left(36^{\circ} \mathrm{C} / 28^{\circ} \mathrm{C}\right.$, day/night temperature $)$, and the light intensity is the same as the normal. High temperature and strong light $(\mathrm{HT}+\mathrm{SL})$ : the average temperature was maintained at $32^{\circ} \mathrm{C}\left(36^{\circ} \mathrm{C} / 28^{\circ} \mathrm{C}\right.$, day and night temperature), and the light intensity was set at $1,600 \mu \mathrm{mol} \cdot \mathrm{m}^{-2} \cdot \mathrm{s}^{-1}$ (Table 1).

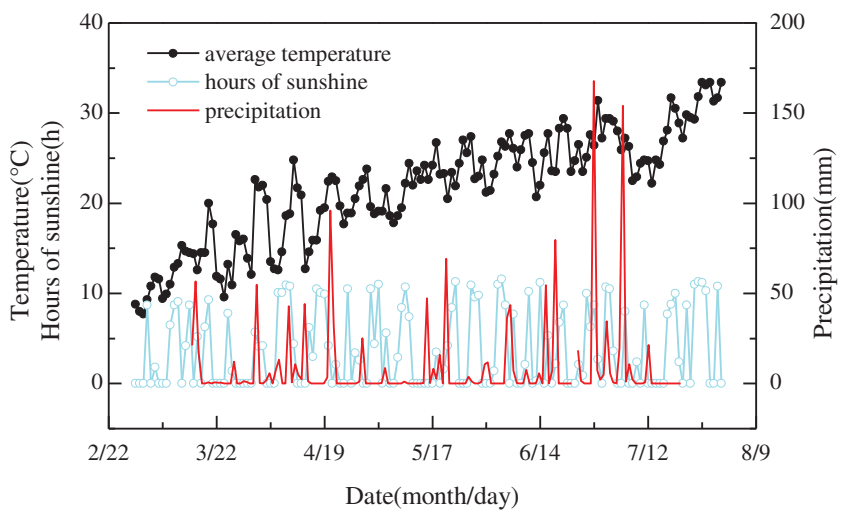

Figure 1: Average temperature, sunshine hours and precipitation of outdoor during early rice growing period

Table 1: Dynamic temperature, light intensity and relative humidity of climate chamber at different time of each day during grouting

\begin{tabular}{lllllll}
\hline Treatment & \multicolumn{2}{l}{ The average temperature for each period $\left({ }^{\circ} \mathrm{C}\right)$} & $\begin{array}{l}\text { Light intensity } \\
\left(\mu \mathrm{mol} \cdot \mathrm{m}^{-2} \cdot \mathrm{s}^{-1}\right)\end{array}$ & $\begin{array}{l}\text { Relative } \\
\text { Humidity }(\%)\end{array}$ \\
\cline { 2 - 7 } & $0000-0600$ & $0600-1200$ & $1200-1800$ & $1800-2400$ & $0700-1900$ & $0000-2400$ \\
\hline CK & 24 & 32 & 24 & 16 & 1000 & 75 \\
HT & 24 & 32 & 40 & 32 & 1000 & 75 \\
HT+SL & 24 & 32 & 40 & 32 & 1600 & 75 \\
\hline
\end{tabular}

Note: CK, normal temperature and normal light; HT, high-temperature and normal light; HT+SL, high-temperature and strong light. 
For the pot experiment, the rice seeds were sown on March 25 and transplanted on April 27. The level of fertilization is the same as the local general cultivation habits. The inorganic fertilizers application rate of nitrogen, phosphorus and potassium fertilizer was $2.5 \mathrm{~g}$ urea, $4.8 \mathrm{~g}$ calcium magnesium phosphate and $1.2 \mathrm{~g}$ potassium chloride, respectively. Nitrogen fertilizer was split-applied for $50 \%$ at basal, $20 \%$ at early tillering, and 30\% at panicle initiation. All phosphorus fertilizer was applied at the basal. $70 \%$ potassium was applied at basal and the remainder was applied at panicle initiation. And 30 pots were planted in each treatment. The early stage of the potting experiment (seeding-heading) was carried out outdoors. At the end of the full heading stage, sixty pots of two rice cultivars were transferred from the natural environment to three climatic chambers. Rice plants at the grout-filling stage were treated in climate chamber and harvested at the maturity stage. During the trial, all rice plants maintained the same management measures both chamber and in the natural environment.

During the grout filling period, in order to make the climate chamber better consistent with the outdoor natural conditions, different temperature gradients of the climate chamber were set continuously day and night temperature according to the changes of natural conditions. The illumination time is set at $12 \mathrm{~h}$ a day (0700-1900), the relative humidity of the climate chamber is maintained at a constant $75 \%$, and the carbon dioxide is $380 \mu \mathrm{mol} \cdot \mathrm{mol}^{-1}$. The climate chamber adopts meteorological instruments $(3400 \times$ $2053 \times 3000$-II; Fujian Jiupu Biological Technology Co., Ltd., China) to adjust the temperature, so as to maintain the constant temperature fluctuation of each time period every day.

\subsection{Yield and Its Components}

Five pots were taken from each treatment at the maturity stage for measuring theoretical yield, investigating the number of grains per panicle and the weight of 1,000 grains, and calculating the filled grain rate [18].

\subsection{Processing and Appearance Quality}

Processing and appearance were measured in accordance with the national standard of the People's Republic of China GB/T 17891-2017 standard operating procedures for high-quality rice [2]. Brown rice rate and milled rice rate were measured by brown rice machine (YS80-4-400, Suzhou Yongyuan Motor Co., Ltd., China) and milled rice machine (YS80-4-400, Suzhou Yongyuan Motor Co., Ltd., China), respectively; and the head milled rice rate, chalky degree and chalky rate were measured by rice quality appearance scanner (MRS-9600TFU2L, Shanghai Zhongjing Technology Co., Ltd., China).

\subsection{Amylose Content}

The amylose content was determined according to the national standard for rice quality evaluation 'GB/T 17891-2017', the People's Republic of China (NBQTC, 2017) [19]. In a nutshell, $100 \mathrm{mg}$ of rice flour was placed into a $100 \mathrm{~mL}$ volumetric flask; then $1 \mathrm{~mL}$ of $95 \%$ ethanol and $9 \mathrm{~mL}$ of $1 \mathrm{~mol} \cdot \mathrm{L}^{-1}$ aqueous sodium hydroxide was added, and the contents were boiled for $8 \mathrm{~min}$. After cooling for $1 \mathrm{~h}$, the volume was made up with distilled water; $5 \mathrm{~mL}$ distilled water was added to a $100 \mathrm{~mL}$ volumetric flask, and $1 \mathrm{~mL}$ of $1 \mathrm{~mol} \cdot \mathrm{L}^{-1}$ aqueous acetic acid and $2 \mathrm{~mL}$ of iodine solution $(0.2 \mathrm{~g}$ iodine and $2.0 \mathrm{~g}$ potassium iodide in $100 \mathrm{~mL}$ aqueous solution) were added and the volume was made up with distilled water. The absorbance of the solution was measured at $620 \mathrm{~nm}$ with a spectrophotometer.

\subsection{Gel Consistency}

Two samples of $100 \mathrm{mg}$ rice flour were put in the test tube, added $0.2 \mathrm{~mL} 0.025 \%$ bromothymol blue solution; then $2.0 \mathrm{~mL} 0.2 \mathrm{~mol} \cdot \mathrm{L}^{-1}$ potassium hydroxide solution was added to it for mixing; and then the test tube was put in the boiling water bath. The opening of the test tube was covered with a glass bullet ball and

heated for $8 \mathrm{~min}$. The test tube was taken out and stood and cooled for $5 \mathrm{~min}$, and then the test tube was put in 
the ice water bath of about $0^{\circ} \mathrm{C}$ to cool for $20 \mathrm{~min}$. Immediately, it was placed horizontally on the operating table laid with coordinate paper and adjusted horizontally in advance, and let it stand for $1 \mathrm{~h}$ at room temperature of $25 \pm 2{ }^{\circ} \mathrm{C}$. The flowing length $(\mathrm{mm})$ of rice glue in the test tube was measured immediately to ensure that the error of the two test results was not more than $7 \mathrm{~mm}$. The average value was taken as the measurement result.

\subsection{Nutritional Quality}

Protein content Nitrogen content in milled rice was determined by Kjeldahl method and then multiplied by conversion coefficient 5.95 [2]. In brief, $0.1 \mathrm{~g}$ rice flour was added to the test tube. Concentrated sulfuric acid $3.5 \mathrm{~mL}$ were added to the test tube with the pipette, then added a dropper of $30 \%$ hydrogen peroxide, and then it was digested. Next, $30 \%$ hydrogen peroxide was added to it to boil for $1 \mathrm{~h}$, and then digested was stopped for an hour to see the situation and added some 30\% hydrogen peroxide. Finally, 30\% hydrogen peroxide was added again. The Kjeldahl apparatus is set for both boric acid and based for two seconds. During distillation, the color of the cone flask was changed from red to light green, and the volume of the distilled liquid is about $50 \mathrm{~mL}$, and titration can be carried out.

\subsection{RVA Viscosity Characteristics of Rice Flour}

The viscosity of rice flour was determined by a rapid viscosity analyzer (RVA) (Newport Scientific Pvt. Ltd., Warier Wood, Australia). $3 \mathrm{~g}$ of rice flour and $25 \mathrm{~g}$ of distilled water were mixed in an RVA aluminum can. A heating and cooling cycle was used. Firstly, the prepared sample at $50^{\circ} \mathrm{C}$ was held for $1 \mathrm{~min}$, and then it was heated to $95^{\circ} \mathrm{C}$ for $3.8 \mathrm{~min}$, and was held at $95^{\circ} \mathrm{C}$ for $2.5 \mathrm{~min}$; when it was cooled to $50^{\circ} \mathrm{C}$ for $3.8 \mathrm{~min}$, and was held at $50^{\circ} \mathrm{C}$ for $1.4 \mathrm{~min}$. The main primary parameters of the reading instrument are peak viscosity $(\mathrm{PV})$, trough viscosity $(\mathrm{TV})$, final viscosity $(\mathrm{FV})$ and pasting temperature $(\mathrm{PaT})$. The secondary parameters are breakdown viscosity $(\mathrm{BD}=\mathrm{PV}-\mathrm{TV})$ and setback viscosity $(\mathrm{SB}=\mathrm{FV}-\mathrm{PV})$. Each sample is measured for three times [20].

\subsection{Statistics and Analysis}

The experimental data are the average value of each treatment with three repeats, and the figures were prepared from Originpro8.5 software (Origin Lab, Northampton, USA). ANOVA and the mean values were performed with SPSS 25.0 statistical software (SPSS Inc., Chicago, USA) to determine the least significant difference (LSD) at $P<0.05$ level.

\section{Results}

\subsection{Yield and Its Components}

The filled grain rate and yield were significantly different in the treatments $(\mathrm{T})$ and the cultivars $(\mathrm{C})$, whereas grains per panicle were notably different in the cultivars and 1000-grain weight was significantly different in the treatments. 1000-grain weight was significantly affected by the interaction on $\mathrm{C} \times \mathrm{T}$ (Table 2). Compared with CK, the yield of two cultivars whether with high or low amylose content significantly decreased under HT and HT+SL. The filled grain rate of XZX45 and ZJZ17 under HT decreased by $32.07 \%, 51.35 \%$, respectively; and decreased by $31.93 \%, 58.85 \%$ under HT+SL, respectively. The 1000-grain weight under HT decreased by $3.64 \%$, $8.01 \%$, while reduced by $5.70 \%$, $21.06 \%$ under $\mathrm{HT}+\mathrm{SL}$ condition, respectively. Compared with HT, HT+SL significantly reduced the yield of ZJZ17, but no significant difference was found in XZX45. The 1000-grain weight of ZJZ17 significantly decreased under HT+SL. 
Table 2: Effects of high temperature and strong light on yield and yield components of early indica rice during grout filling stage

\begin{tabular}{lllllll}
\hline $\begin{array}{l}\text { Cultivar } \\
(\mathrm{C})\end{array}$ & $\begin{array}{l}\text { Treatment } \\
(\mathrm{T})\end{array}$ & $\begin{array}{l}\text { Effective panicles/ } \\
\left(\text { pot }^{-1}\right)\end{array}$ & $\begin{array}{l}\text { Grains per } \\
\text { panicle }\end{array}$ & $\begin{array}{l}\text { Filled Grain } \\
\text { rate/(\%) }\end{array}$ & $\begin{array}{l}\text { 1000-grain } \\
\text { weight/g }\end{array}$ & $\begin{array}{l}\text { Yield/ } \\
\left(\mathrm{g} \cdot \text { pot }^{-1}\right)\end{array}$ \\
\hline XZX 45 & CK & $17.6 \mathrm{a}$ & $106.6 \mathrm{a}$ & $83.0 \mathrm{a}$ & $23.8 \mathrm{a}$ & $25.4 \mathrm{a}$ \\
& $\mathrm{HT}$ & $17.0 \mathrm{a}$ & $106.0 \mathrm{a}$ & $56.3 \mathrm{~b}$ & $22.0 \mathrm{~b}$ & $12.0 \mathrm{c}$ \\
& $\mathrm{HT}+\mathrm{SL}$ & $17.2 \mathrm{a}$ & $106.1 \mathrm{a}$ & $56.4 \mathrm{~b}$ & $21.5 \mathrm{~b}$ & $12.9 \mathrm{c}$ \\
ZJZ 17 & $\mathrm{CK}$ & $16.8 \mathrm{a}$ & $81.3 \mathrm{~b}$ & $85.3 \mathrm{a}$ & $24.2 \mathrm{a}$ & $20.8 \mathrm{~b}$ \\
& $\mathrm{HT}$ & $16.4 \mathrm{a}$ & $81.0 \mathrm{~b}$ & $41.5 \mathrm{c}$ & $22.3 \mathrm{~b}$ & $10.4 \mathrm{c}$ \\
& $\mathrm{HT}+\mathrm{SL}$ & $16.2 \mathrm{a}$ & $81.2 \mathrm{~b}$ & $35.1 \mathrm{c}$ & $19.1 \mathrm{c}$ & $6.1 \mathrm{~d}$ \\
& $\mathrm{C}$ & $\mathrm{NS}$ & $* *$ & $* *$ & $*$ & $* *$ \\
& $\mathrm{~T}$ & $\mathrm{NS}$ & $\mathrm{NS}$ & $* *$ & $* *$ & $* *$ \\
& $\mathrm{C} \times \mathrm{T}$ & $\mathrm{NS}$ & $\mathrm{NS}$ & $*$ & $* *$ & $\mathrm{NS}$ \\
\hline
\end{tabular}

Notes: Values with different letters in the same column are significantly different with $P<0.05$. NS, no significance; * and **, significant differences at the 0.05 and 0.01 probability levels, respectively. CK, normal temperature and normal light; HT, high-temperature and normal light; HT+SL, hightemperature and strong light. XZX45, Xiangzaoxian45; ZJZ17, Zhongjiazao17.

\subsection{Processing and Appearance Quality}

The differences in milled rice rate, head rice rate and chalky rate were significant in the cultivars and treatments, and the differences in brown rice rate and chalky degree were significant in the treatments. The differences in milled rice rate, head rice rate were also significant on the $\mathrm{C} \times \mathrm{T}$ (Table 3). Compared with $\mathrm{CK}$, the brown rice rate and head rice rate of the cultivars significantly decreased under HT and HT + SL conditions, while the chalky rate and chalky degree significantly increased, indicating that HT can deteriorate the processing and appearance quality of rice whether in high/low amylose content cultivars. Compared with HT, the brown rice rate and head rice rate of low amylose content cultivar XZX45 significantly reduced under HT+SL, whereas the brown rice rate, milled rice rate, head rice rate and chalky rate of high amylose content cultivar ZJZ17 significantly increased. The changes of the two cultivars were not consistent, implying that the effects of SL on rice processing and appearance quality were different among different amylose content cultivars under the same high-temperature condition.

Table 3: Effects of high temperature and strong light on processing and appearance quality of early indica rice during grout filling stage

\begin{tabular}{llllllll}
\hline $\begin{array}{l}\text { Cultivar } \\
(\mathrm{C})\end{array}$ & $\begin{array}{l}\text { Treatment } \\
(\mathrm{T})\end{array}$ & $\begin{array}{l}\text { Brown rice } \\
\text { rate }(\%)\end{array}$ & $\begin{array}{l}\text { Milled rice } \\
\text { rate }(\%)\end{array}$ & $\begin{array}{l}\text { Head rice } \\
\text { rate }(\%)\end{array}$ & $\begin{array}{l}\text { Length- } \\
\text { width ratio }\end{array}$ & $\begin{array}{l}\text { Chalky } \\
\text { rate }(\%)\end{array}$ & $\begin{array}{l}\text { Chalky } \\
\text { degree (\%) }\end{array}$ \\
\hline XZX45 & $\mathrm{CK}$ & $84.6 \mathrm{~b}$ & $67.4 \mathrm{~b}$ & $52.9 \mathrm{a}$ & $2.1 \mathrm{~b}$ & $19.1 \mathrm{~d}$ & $5.9 \mathrm{~b}$ \\
& $\mathrm{HT}$ & $79.3 \mathrm{c}$ & $59.1 \mathrm{~d}$ & $43.7 \mathrm{~d}$ & $2.2 \mathrm{~b}$ & $99.2 \mathrm{a}$ & $70.2 \mathrm{a}$ \\
& $\mathrm{HT}+\mathrm{SL}$ & $70.1 \mathrm{f}$ & $58.6 \mathrm{~d}$ & $41.3 \mathrm{e}$ & $2.1 \mathrm{~b}$ & $98.9 \mathrm{ab}$ & $70.9 \mathrm{a}$ \\
$\mathrm{ZJZ17}$ & $\mathrm{CK}$ & $86.1 \mathrm{a}$ & $70.2 \mathrm{a}$ & $51.3 \mathrm{~b}$ & $2.8 \mathrm{a}$ & $11.2 \mathrm{e}$ & $3.6 \mathrm{~b}$ \\
& $\mathrm{HT}$ & $71.8 \mathrm{e}$ & $59.8 \mathrm{~d}$ & $41.9 \mathrm{e}$ & $2.6 \mathrm{a}$ & $93.4 \mathrm{c}$ & $67.8 \mathrm{a}$ \\
& $\mathrm{HT}+\mathrm{SL}$ & $76.1 \mathrm{~d}$ & $63.0 \mathrm{c}$ & $47.7 \mathrm{c}$ & $2.9 \mathrm{a}$ & $95.9 \mathrm{~b}$ & $68.9 \mathrm{a}$ \\
& $\mathrm{C}$ & $\mathrm{NS}$ & $* *$ & $* *$ & $* *$ & $* *$ & $\mathrm{NS}$ \\
& $\mathrm{T}$ & $* *$ & $* *$ & $* *$ & $\mathrm{NS}$ & $* *$ & $* *$ \\
& $\mathrm{C} \times \mathrm{T}$ & $* *$ & $* *$ & $* *$ & $\mathrm{NS}$ & $*$ & $\mathrm{NS}$ \\
\hline
\end{tabular}

Notes: Values with different letters in the same column are significantly different with $P<0.05$. NS, no significance; * and **, significant differences at the 0.05 and 0.01 probability levels, respectively. CK, normal temperature and normal light; HT, high-temperature and normal light; HT+SL, hightemperature and strong light. XZX45, Xiangzaoxian45; ZJZ17, Zhongjiazao17. 


\subsection{Cooking and Eating and Nutritional Quality}

The differences in amylose content, protein and gel consistency were significant in the cultivars and treatments, and the differences were significantly affected by the interaction on $\mathrm{C} \times \mathrm{T}$ (except for amylose content) (Table 4). Compared with CK, the amylose content significantly decreased under HT and $\mathrm{HT}+\mathrm{SL}$, while the protein content of the two cultivars and the gel consistency of XZX45 significantly increased. Compared with HT, HT+SL significantly increased amylose content in ZJZ17, whereas significantly decreased gel consistency in the cultivars, indicating that SL can promote the synthesis of amylose in high amylose content cultivar ZJZ17 under the same high-temperature condition. The amylose content of the high amylose cultivar ZJZ17 was greatly affected by HT+SL contrast to XZX45 with low amylose content.

Table 4: Effects of high temperature and strong light on cooking and eating and nutritional quality of early indica rice during grout filling stage (\%)

\begin{tabular}{lllll}
\hline Cultivar (C) & Treatment (T) & Amylose content & Protein content & Gel consistency \\
\hline XZX45 & CK & $17.7 \mathrm{~d}$ & $8.3 \mathrm{c}$ & $48.1 \mathrm{~d}$ \\
& HT & $13.0 \mathrm{e}$ & $10.7 \mathrm{~b}$ & $88.9 \mathrm{a}$ \\
& HT+SL & $13.4 \mathrm{e}$ & $11.0 \mathrm{~b}$ & $58.3 \mathrm{c}$ \\
ZJZ17 & CK & $24.1 \mathrm{a}$ & $8.5 \mathrm{c}$ & $20.0 \mathrm{e}$ \\
& HT & $20.1 \mathrm{c}$ & $13.1 \mathrm{a}$ & $69.1 \mathrm{~b}$ \\
& HT+SL & $21.1 \mathrm{~b}$ & $13.0 \mathrm{a}$ & $16.9 \mathrm{f}$ \\
& $\mathrm{C}$ & $* *$ & $* *$ & $* *$ \\
& $\mathrm{~T}$ & $* *$ & $* *$ & $* *$ \\
& $\mathrm{C} \times \mathrm{T}$ & $\mathrm{NS}$ & $* *$ & $* *$ \\
\hline
\end{tabular}

Notes: Values with different letters in the same column are significantly different with $P<0.05$. NS, no significance; * and **, significant differences at the 0.05 and 0.01 probability levels, respectively. CK, normal temperature and normal light; HT, high-temperature and normal light; HT+SL, hightemperature and strong light. XZX45, Xiangzaoxian45; ZJZ17, Zhongjiazao17.

\subsection{RVA Viscosity Characteristics of Rice Flour}

The RVA viscosity characteristics of rice flour were shown in Fig. 2. Differences in the viscosity characteristics were significant in the cultivars, treatments and the interaction on $\mathrm{C} \times \mathrm{T}$ (Table 5). The trough viscosity, final viscosity, setback viscosity (SB) and pasting temperature (PaT) were significantly increased, whereas peak viscosity and breakdown viscosity (BD) significantly decreased in the cultivars under HT and $\mathrm{HT}+\mathrm{SL}$ conditions contrast to $\mathrm{CK}$, indicating that the cooking and eating quality of rice was deteriorated by HT and HT+SL. Compared with HT, the trough viscosity, final viscosity and peak viscosity were significantly decreased for two cultivars under HT+SL, whereas the BD and SB only significantly decreased in ZJZ17, indicating that SL had a greater effect on eating quality for ZJZ17 than that of XZX45 under the same high-temperature condition.

\section{Discussion}

\subsection{Effects of High Temperature and Strong Light on Yield and Its Components of Early Indica Rice during Grout Filling Stage}

Rice grain weight significantly decreased under higher temperature, especially when the grout filling process was under high temperature [21,22]. In this study, HT and HT+SL significantly decreased the grain yield and the 1000-grain weight, filled grain rate in the two cultivars with different amylose content. Previous studies have shown that high temperature from heading to maturity can affect rice grout filling 
rate, thus shortening grout filling duration and accelerating ripening, grout filling fullness decreased, resulting in lower 1000-grain weight, filled grain rate and significantly lower yield $[7,18]$. There was a certain relationship between the yield components in the cultivars with different amylose content. 1000grain weight and grain number per panicle of high amylose content cultivars were significantly higher than those of low amylose content cultivars [23]. In the present study, HT+SL significantly reduced the grain yield and 1000-grain weight of high amylose content cultivar ZJZ17 contrast to HT. Light intensity affects rice grout filling fullness by affecting rice photosynthesis; too strong or low light inhibits the accumulation of photosynthates, and changes the movement of photochemical products, resulting in reducing grout fullness, 1000-grain weight and yield of rice [24].
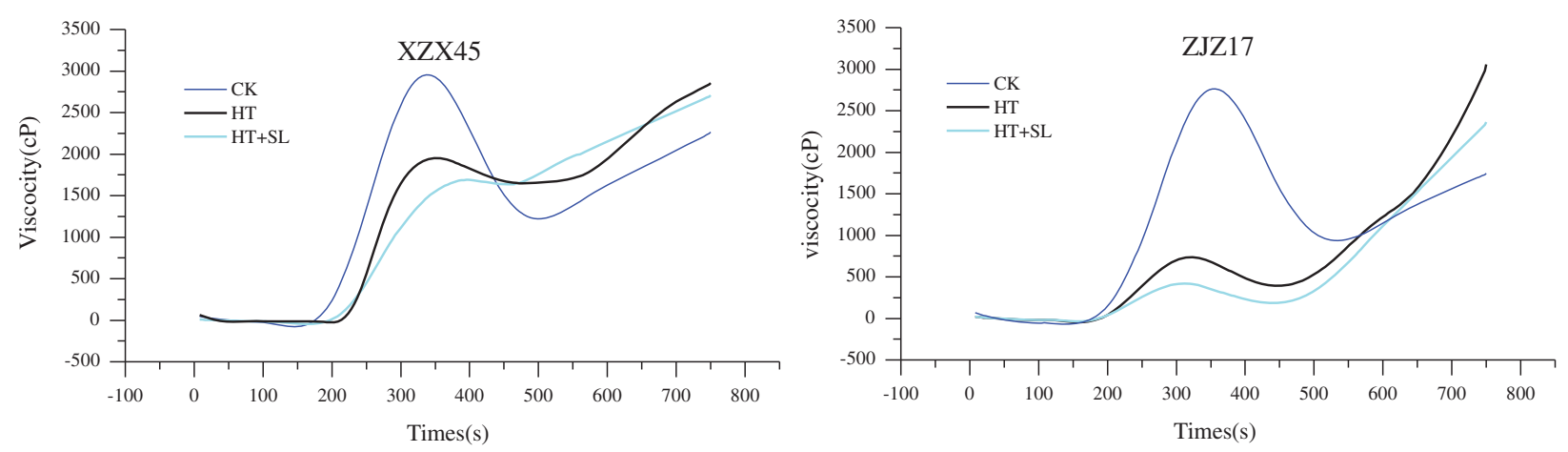

Figure 2: Effect of high temperature and strong light on RVA viscosity characteristics of early indica rice flour during grout filling. XZX45, Xiangzaoxian45; ZJZ17, Zhongjiazao17

\subsection{Effects of High Temperature and Strong Light on Grain Quality of Early Indica Rice during Grout Filling Stage}

Most studies have shown that temperature changes will change the starch of caryopsis, storage protein and other chemical components during grout filling, thus affecting rice quality [12,25,26]. Our study showed that the brown rice rate, milled rice rate and head rice rate significantly reduced under HT and HT+SL, which was in agreement with the results of the previous study [18]. The main reason is that high temperature increased the chalky rate and chalky degree of the rice cultivars. The more chalkiness area, the more rice will be broken incompletely during the processing [7], and the processing and appearance quality will deteriorate [24]. HT and HT+SL stress led to a significant decrease in amylose content in the cultivars, which may be due to the inhibition of GBSS activity [27]. Yoshida et al. [24] also reported that the amylose content of rice decreased with the increase of temperature, and the degree of decline varied in the different cultivars. It is generally believed that rice with better eating quality has lower amylose content $[28,29]$. Therefore, HT seemed to improve the eating quality of rice with relatively high gel consistency.

In this study, HT and HT + SL increased protein content, which was consistent with the previous studies [26]. In general, the CEQ of rice tended to get worse with the increase of protein content [30]. Furthermore, trough viscosity, final viscosity, setback viscosity and PaT were significantly increased by HT and HT+SL, but peak viscosity and breakdown significantly decreased in the cultivars. Previous studies also reported similar results that high temperature increased SB and decreased BD, and the pasting viscosity becomes worse [31,32]. Generally, the rice with higher BD and lower SB has better eating characteristics [29]. However, for the present results, HT and HT+SL could deteriorate eating quality. In addition, HT and HT $+\mathrm{SL}$ increased the pasting temperature, suggesting that higher cooking temperature and time were required to cook the rice, and the cooking quality of rice became worse. 
Table 5: Effects of high temperature and strong light on RVA viscosity characteristics of early indica rice flour during grout filling stage

\begin{tabular}{llllllll}
\hline Cultivars (C) & Treatment (T) & TV $(\mathrm{cP})$ & FV (cP) & PV $(\mathrm{cP})$ & PaT $\left({ }^{\circ} \mathrm{C}\right)$ & BD $(\mathrm{cP})$ & SB $(\mathrm{cP})$ \\
\hline XZX45 & CK & $1120.0 \mathrm{c}$ & $2416.7 \mathrm{~d}$ & $3095.7 \mathrm{a}$ & $78.7 \mathrm{~d}$ & $1975.7 \mathrm{~b}$ & $-679.0 \mathrm{~d}$ \\
& $\mathrm{HT}$ & $1774.0 \mathrm{a}$ & $2875.7 \mathrm{~b}$ & $2013.7 \mathrm{~b}$ & $83.0 \mathrm{ab}$ & $239.7 \mathrm{~d}$ & $862.0 \mathrm{c}$ \\
& $\mathrm{HT}+\mathrm{SL}$ & $1533.7 \mathrm{~b}$ & $2744.0 \mathrm{c}$ & $1788.0 \mathrm{c}$ & $82.1 \mathrm{~b}$ & $254.3 \mathrm{~d}$ & $956.0 \mathrm{c}$ \\
ZJZ17 & $\mathrm{CK}$ & $822.0 \mathrm{~d}$ & $1811.7 \mathrm{e}$ & $3013.3 \mathrm{a}$ & $80.6 \mathrm{c}$ & $2191.3 \mathrm{a}$ & $-1201.7 \mathrm{e}$ \\
& HT & $372.3 \mathrm{e}$ & $3200.3 \mathrm{a}$ & $806.3 \mathrm{~d}$ & $82.6 \mathrm{ab}$ & $434.0 \mathrm{c}$ & $2394.0 \mathrm{a}$ \\
& $\mathrm{HT}+\mathrm{SL}$ & $177.3 \mathrm{f}$ & $2363.0 \mathrm{~d}$ & $428.7 \mathrm{e}$ & $83.9 \mathrm{a}$ & $251.3 \mathrm{~d}$ & $1934.3 \mathrm{~b}$ \\
& $\mathrm{C}$ & $* *$ & $* *$ & $* *$ & $*$ & $* *$ & $* *$ \\
& $\mathrm{~T}$ & $* *$ & $* *$ & $* *$ & $* *$ & $* *$ & $* *$ \\
& $\mathrm{C} \times \mathrm{T}$ & $* *$ & $* *$ & $* *$ & $*$ & $*$ & $* *$ \\
\hline
\end{tabular}

Notes: Values with different letters in the same column are significantly different with $P<0.05$. NS, no significance; $*$ and $* *$, significant differences at the 0.05 and 0.01 probability levels, respectively. CK, normal temperature and normal light; HT, high-temperature and normal light; HT+SL, hightemperature and strong light; PV, peak viscosity; TV, trough viscosity; FV, final viscosity; BD, breakdown viscosity; SB, setback viscosity; PaT, pasting temperature. XZX45: Xiangzaoxian45; ZJZ17: Zhongjiazao17.

In addition, compared with HT, the amylose content of the two cultivars increased under $\mathrm{HT}+\mathrm{SL}$, especially for ZJZ17, indicating that SL could promote the synthesis of amylose under high-temperature condition. HT+SL decreased the brown rice rate, milled rice rate, head rice rate and chalky rice rate of XZX45, while increasing those of ZJZ17. The main reason may be that the change of light intensity affects the physiochemical metabolism and quality of rice during the process of grain formation [15]. However, the cultivars with different plant genotypes have different light-response properties [33], suggesting that the quality changes of the two cultivars had different responses to SL under single high temperature.

\section{Conclusion}

In this study, compared with CK, HT and HT+SL reduced filled grain rate and 1000-grain weight during grout filling stage whether in high or low amylose content early indica rice cultivars, and resulted in a significant decrease in rice yield. The rate of milled rice, brown rice and head rice significantly decreased, while chalky rate and chalky degree significantly increased under HT and HT+SL. Meanwhile, HT and $\mathrm{HT}+\mathrm{SL}$ significantly decreased amylose content, whereas increased protein content, and also significantly decreased pasting viscosities such as high TV, FV, PV and SB, PaT and low BD, resulting in worse processing, appearance and cooking and eating quality of rice, and the responses to the treatments in the rice cultivars were basically similar. Compared with HT, HT + SL had different effects on rice yield and quality, but $\mathrm{HT}+\mathrm{SL}$ overall had more significant negative effect on the rice cultivar ZJZ17 with high amylose content.

Funding Statement: The study was funded by the National Key Research \& Development Project of China (2016YFD0300501) and the Key Project of Jiangxi Provincial Natural Science Foundation (20202ACBL215004), the Key Research of \& Development Project Jiangxi Province, China (20171BBF60030). We would also like to thank those who have been at the forefront of fight against the COVID-19 epidemic for allowing us to concentrate on writing this paper securely.

Conflicts of Interest: The authors declare that they have no known competing financial interests or personal relationships that could have appeared to influence the work reported in this paper. 


\section{References}

1. Zhang, C. Q., Zhou, L. H., Zhu, Z. B., Lu, H. W., Zhou, X. Z. et al. (2016). Characterization of grain quality and starch fine structure of two japonica rice (Oryza sativa L.) cultivars with good sensory properties at different temperatures during the filling stage. Journal of Agricultural \& Food Chemistry, 64(20), 4048-4057. DOI 10.1021/acs.jafc.6b00083.

2. Yang, T. T., Hu, Q. X., Huang, S., Zeng, Y. H., Tan, X. M. et al. (2018). Response of yield and quality of doublecropping high-quality rice cultivars under free-air temperature increasing. Chinese Journal of Rice Science, 32, 572-580 (in Chinese with English abstract). DOI 10.16819/j.1001-7216.2018.8050.

3. Chen, J., Tang, L., Shi, P., Yang, B., Sun, T. et al. (2017). Effects of short-term high temperature on grain quality and starch granules of rice (Oryza sativa L.) at post-anthesis stage. Protoplasma, 254(2), 935-943. DOI 10.1007/ s00709-016-1002-y.

4. Toshio, T. (2008). Relation between mean air temperature during ripening period of rice and amylographic characteristics or cooking quality. Japanese Journal of Crop Science, 68(1), 45-47. DOI 10.1626/jcs.68.45.

5. Lin, C. J., Li, C. Y., Lin, S. K., Yang, F. H., Huang, J. J. et al. (2014). Influence of high temperature during grain filling on the accumulation of storage proteins and grain quality in rice (Oryza sativa L.). Journal of Agricultural \& Food Chemistry, 58(19), 10545-10552. DOI 10.1021/jf101575j.

6. Zhong, L. J., Cheng, F. M., Wen, X., Sun, Z. X., Zhang, G. P. et al. (2005). The deterioration of eating and cooking quality caused by high temperature during grain filling in early-season indica rice cultivars. Journal of Agronomy and Crop Science, 191(3), 218-225. DOI 10.1111/j.1439-037X.2005.00131.x.

7. Rehmani, M., Wei, G., Hussain, N., Ding, C., Li, G. et al. (2014). Yield and quality responses of two indica rice hybrids to post-anthesis asymmetric day and night open-field warming in lower reaches of Yangtze River delta. Field Crops Research, 156, 231-241. DOI 10.1016/j.fcr.2013.09.019.

8. Li, T., Ohsugi, R., Yamagishi, T., Sasaki, H. (2006). Effects of weak light on starch accumulation and starch synthesis enzyme activities in rice at the grain filling stage. Rice Science, 13(6), 51-58. DOI 10.1360/aps040074.

9. Dou, Z., Tang, S., Chen, W. Z., Zhang, H. X., Li, G. H. et al. (2018). Effects of open-field warming during grainfilling stage on grain quality of two japonica rice cultivars in lower reaches of Yangtze River delta. Journal of Cereal Science, 81, 118-126. DOI 10.1016/j.jcs.2018.04.004.

10. Ahmed, N., Tetlow, I. J., Nawaz, S., Iqbal, A., Mubin, M. et al. (2015). Effect of high temperature on grain filling period, yield, amylase content and activity of starch biosynthesis enzymes in endosperm of basmati rice. Journal of the Science of Food and Agriculture, 95(11), 2237-2243. DOI 10.1002/jsfa.6941.

11. Tang, S., Chen, W., Liu, W., Zhou, Q., Zhang, H. et al. (2018). Open-field warming regulates the morphological structure, protein synthesis of grain and affects the appearance quality of rice. Journal of Cereal Science, 84, 2029. DOI 10.1016/j.jcs.2018.09.013.

12. Asaoka, M., Kazutoshi, O., Fuwa, H. (1985). Effect of environmental temperature at the milky stage on amylose content and fine structure of amylopectin of waxy and nonwaxy endosperm starches of rice (Oryza sativa L.). Agricultural and Biological Chemistry, 49(2), 373-379. DOI 10.1080/00021369.1985.10866741.

13. Ashida, K., Araki, E., Maruyama-Funatsuki, W., Fujimoto, H., Ikegami, M. (2013). Temperature during grain ripening affects the ratio of type-II/type-I protein 10 body and starch pasting properties of rice (Oryza sativa L.). Journal of Cereal Science, 57(1), 153-159. DOI 10.1016/j.jcs.2012.10.006.

14. Yi, C., Zhao, Z., Tao, F. (2018). Impacts of climate change and climate extremes on major crops productivity in China at a global warming of 1.5 and $2.0^{\circ}$ C. Earth System Dynamics, 9, 1-27. DOI 10.5194/esd-2017-99.

15. Liu, Q. H., Wu, X., Chen, B. C., Ma, J. Q., Gao, J. (2014). Effects of low light on agronomic and physiological characteristics of rice including grain yield and quality. Rice Science, 21(5), 243-251. DOI 10.1016/S1672-6308 (13)60192-4.

16. Ren, W. J., Yang, W. Y., Xu, J. W., Fan, G. Q., Ma, Z. H. (2003). Effect of low light on grains growth and quality in rice. Acta Agronomica Sinica, 29(5), 785-790. DOI 10.3321/j.issn: 0496-3490.2003.05.027.

17. Ahmed, N., Maekawa, M., Tetlow, I. J. (2008). Effects of low temperature on grain filling, amylose content, and activity of starch biosynthesis enzymes in endosperm of basmati rice. Australian Journal of Agricultural Research, 59(7), 599-604. DOI 10.1071/AR07340. 
18. Xiong, D., Ling, X., Huang, J., Peng, S. (2017). Meta-analysis and dose-response analysis of high temperature effects on rice yield and quality. Environmental and Experimental Botany, 141, 1-9. DOI 10.1016/j. envexpbot.2017.06.007.

19. NBQTC (2017). National bureau of quality and technology control. The national standard for rice quality evaluation (GB/T 17891/2017). Beijing, China (in Chinese).

20. Bao, J., Shen, S., Mei, S., Corke, H. (2006). Analysis of genotypic diversity in the starch physicochemical properties of nonwaxy rice: Apparent amylose content, pasting viscosity and gel texture. Starch-Starke, 58, 259-267. DOI 10.1002/(ISSN)1521-379X.

21. Morita, S. (2008). Prospect for developing measures to prevent high-temperature damage to rice grain ripening. Japanese Journal of Crop Science, 77(1), 1-12. DOI 10.1626/jcs.77.1.

22. Fahad, S., Hussain, S., Saud, S., Hassan, S., Tanveer, M. et al. (2016). A combined application of biochar and phosphorus alleviates heat-induced adversities on physiological, agronomical and quality attributes of rice. Plant Physiology and Biochemistry, 103(6), 191-198. DOI 10.1016/j.plaphy.2016.03.001.

23. Jin, Z. X., Liu, H. L., Liu, H. Y., Li, X. G., Zhang, Z. C. et al. (2010). Effects of amylose content selection in hybrid progenies of japonica rice on quality and yield traits and genetic diversity. Molecular Plant Breeding, 8(9-10), 446-454. DOI 10.1016/S1872-2067(10)60116-7.

24. Yoshida, S., Hara, T. (1977). Effect of air temperature and light on grain filling of an indica and a japonica rice (Oryza sativa L.) under controlled environment conditions. Soil Science \& Plant Nutrition, 23(1), 93-107. DOI 10.1080/00380768.1977.10433026.

25. Nagato, K., Chaudhry, F. M. (1969). A comparative study of ripening process and kernel development in japonica and indica rice. Japanese Journal of Crop Science, 38(3), 425-433. DOI 10.1626/jcs.38.425.

26. Zhi, D., She, T., Chen, W., Zhang, H., Ding, Y. (2018). Effects of open-field warming during grain-filling stage on grain quality of two japonica rice cultivars in lower reaches of Yangtze River delta. Journal of Cereal Science, 81, 118-126. DOI 10.1016/j.jcs.2018.04.004.

27. Yin, Y., Yu, C., Li, Y., Zhao, J., Zhou, G. (2015). The influence of light intensity and photoperiod on duckweed biomass and starch accumulation for bioethanol production. Bioresource Technology, 187(3), 84-90. DOI 10.1016/j.biortech.2015.03.097.

28. Bhat, F. M., Riar, C. S. (2017). Physicochemical, cooking, and textural characteristics of grains of different rice (Oryza sativa L.) cultivars of temperate region of India and their interrelationships. Journal of Texture Studies, 48(2), 160-170. DOI 10.1111/jtxs.12227.

29. Xie, L. H., Luo, J., Tang, S. Q., Chen, N., Jiao, G. A. et al. (2013). Proteins affect rice eating quality properties and its mechanism. Chinese Journal of Rice Science, 27, 91-96. DOI 10.3969/j.issn.1001-7216.2013.01.013.

30. Lin, C. J., Li, C. Y., Lin, S. K., Yang, F. H., Huang, J. J. et al. (2010). Influence of high temperature during grain filling on the accumulation of storage proteins and grain quality in rice (Oryza sativa L.). Journal of Agricultural and Food Chemistry, 13(19), 10545-10552. DOI 10.1021/jf101575j.

31. Tashiro, T. (1991). The effect of high temperature on kernel dimensions and the type and occurrence of kernel damage in rice. Australian Journal of Agricultural Research, 42(3), 485-496. DOI 10.1071/ar9910485.

32. Liao, J. L., Zhou, H. W., Peng, Q., Zhong, P. A., Zhang, H. Y. et al. (2015). Transcriptome changes in rice (Oryza sativa $\mathrm{L}$.) in response to high night temperature stress at the early milky stage. BMC Genomics, 16(1), 3-14. DOI 10.1186/s12864-015-1222-0.

33. Szymańska, R., Lesak, I., Orzechowska, A., Kruk, J. (2017). Physiological and biochemical responses to high light and temperature stress in plants. Environmental and Experimental Botany, 139, 165-177. DOI 10.1016/j. envexpbot.2017.05.002. 